\title{
Geomorfositios en el Geoparque Mundial Unesco de El Hierro (Islas Canarias, España) para fomentar el geoturismo en espacios volcánicos ${ }^{1}$
}

\section{Geomorphosites of El Hierro global Unesco geopark (Canary Islands, Spain) to promote the volcanic geoturism}

\author{
Javier Dóniz Páez² (1), Rafael Becerra-Ramírez³ (1) \\ y Esther Beltrán Yanes ${ }^{4}$ (1)
}

\begin{abstract}
RESUMEN
El Hierro es la isla más occidental y pequeña del archipiélago canario localizado en el Atlántico oriental subtropical. Es una isla de origen volcánico y geológicamente muy joven que fue declarada Geoparque Mundial UNESCO en 2014 por poseer un patrimonio sobresaliente asociado con el volcanismo y presentar espléndidos paisajes donde la geomorfología es la protagonista. La isla recibe varios miles de turistas al año atraídos principalmente por el buceo y el senderismo. El objetivo de este trabajo es identificar, inventariar, seleccionar y valorar veinte geomorfositios volcánicos destacados, conservados y accesibles que tengan interés geoturístico, para fomentar el turismo y que diversifiquen la oferta de ocio en la isla. Los sitios seleccionados incluyen conos volcánicos, campos de lava, plataformas lávicas, fallas, valles de deslizamiento, barrancos, acantilados o playas. Los valores geomorfológicos de estos lugares pueden contribuir a potenciar el geoturismo como una actividad turística y de ocio importante en El Hierro.
\end{abstract}

Palabras claves: Geomorfositios, geoturismo, geoparque volcánico, El Hierro, España.

\begin{abstract}
El Hierro island located in the east Atlantic Ocean subtropical is the most western and the smallest one of the Canaries. It is a volcanic island geologically very recent and it possess a rich and diverse heritage related to volcanism, with scenic landscapes where the geomorphology is the main, and it became a UNESCO Global Geopark in 2014. This island receives thousands of tourists a year mainly motivated by diving and trekking. For this reason, the aim of this work is to identify, inventory, select and value twenty outstan-
\end{abstract}

Este trabajo ha sido posible gracias al proyecto "VOLTURMAC, Fortalecimiento del volcano turismo en la Macaronesia (MAC2/4.6c/298)", cofinanciado por el Programa de Cooperación INTERREG V-A España-Portugal MAC (Madeira-Azores-Canarias) 2014-2020 GEOTURVOL-Departamento de Geografía e Historia, Universidad de La Laguna, Facultad de Humanidades. Instituto Volcanológico de Canarias (INVOLCAN), España. Correo electrónico: jdoniz@ull.edu.es

GEOVOL-Departamento de Geografía y Ordenación del Territorio. Universidad de Castilla-La Mancha, Facultad de Letras. Instituto Volcanológico de Canarias (INVOLCAN), España. Correo electrónico: rafael.becerra@ulcm.es

GEOTURVOL-Departamento de Geografía e Historia, Universidad de La Laguna, Facultad de Humanidades.

Correo electrónico: estyanes@ull.edu.es 


\begin{abstract}
ding volcanic geomorphosites well preserved and accessible with a geoturistic interest, in order to promote the geotourism and to diversify the leisure offer on the island. These sites include cinder cones, lava fields, lava delta, faults, giant landslides, valleys, cliffs and beaches. The selection of these geomorphosites can to contribute geotourism as an important leisure activity.
\end{abstract}

Keywords: Volcanic heritage, Geomorphosites, geotourism, volcanic geopark, El Hierro, Spain

El turismo es una de las principales actividades económicas de nuestro tiempo (OMT, 2019) y pese a las circunstancias actuales provocadas por la pandemia del COVID-19, es un mercado en continuo crecimiento sobre todo vinculado con el sol y la playa. Sin embargo, también es cierto que muchos de los destinos turísticos maduros de sol y playa muestran equipamientos e infraestructuras turísticas obsoletas que se traducen en una disminución de las llegadas de visitantes y el agotamiento del destino (Hernández \& Santana, 2010). Como consecuencia de ello muchos de estos destinos están experimentando transformaciones hacia la creación de nuevos productos y experiencias turísticas, entre las que se encuentra el geoturismo.

La explotación turística de la perspectiva paisajística de la gea se puso de manifiesto con la creación de los primeros parques nacionales en EEUU (Yelowstone, Yosemite), pero es en las últimas décadas cuando ha aumentado significativamente (Farsani et al., 2012; Ólafsdóttir \& Dowling, 2014; Ruban, 2015; Dowling \& Newsone, 2018). A ello ha contribuido, además de otras cuestiones, la creación y consolidación de la red mundial de geoparques. Ahora bien, el geoturismo es un concepto relativamente reciente y una modalidad de turismo novedosa (Pásková \& Zelenka, 2018). Estas dos razones son responsables de que la definición de geoturismo esté aún en pleno debate científico y que bajo el paraguas de este se desarrollen e implementen iniciativas, productos y experiencias turísticas muy diversas entre sí, pero que no tienen por qué ser excluyentes (Dowling \& Newsone, 2018). En este sentido, las ideas de lo que es y lo que comprende el geoturismo se podrían agrupar en torno a dos principales líneas según los diferentes investigadores. Por un lado, aquella en la que subyace la idea de que se trata de un tipo de turismo centrado en la visita de lugares de alto valor escénico determinado por la presencia de recursos geológicos, especialmente vinculados a la geomorfología, que reflejen la evolución de los procesos que modelan las formas del relieve (Hose, 1995, 2008; Newsome \& Dowling, 2010; Carcavilla et al., 2011; Dowling, 2013; Ólafsdóttir \& Tverijonaite, 2018). Y, por otro lado, la que relaciona el geoturismo con una visión más integral, holística y geográfica que amplía la concepción puramente geológica de la definición anterior incluyendo otros valores naturales, culturales e históricos (Tourtellot, 2000; Stoke et al., 2003; Pralong, 2006; National Geographic, 2010, Arouca Declaration, 2011. Millán, 2011; Sánchez-Cortez y Simbaña-Tasiguano, 2018, Olson \& Dowling, 2018; Dóniz-Páez et al., 2019c). En este sentido cabe señalar que cada vez más las publicaciones sobre geoturismo apuestan por el carácter holístico y geográfico del mismo (Millan, 2011; Tourtellot, 2000; Stoke et al., 2003; Pralong, 2006; Sánchez-Cortez y Simbaña-Tasiguano, 2018; Olson \& Dowling, 2018; Dóniz-Páez et al., 2019c).

En este trabajo se ha optado por una concepción más global del geoturismo y su aplicación al geoparque, siendo, además, la primera vez en la isla que se realiza esta selección y evaluación semicuantitativa de diferentes geomorfositios representativos de la diversidad de su relieve. El Hierro se declaró geoparque en septiembre de 2014 y la erupción submarina del año 2011-2012 el Mar de Las Calmas constituyó un hito decisivo para la presentación de la candidatura a geopar- 
que. Este evento volcánico provocó la paralización del buceo y la pesca que son las dos principales actividades económicas en esta zona durante el desarrollo de la erupción y en meses posteriores. Esto desencadenó efectos negativos en la economía insular y promovió la búsqueda de alternativas turísticas y laborales para la población local (Dóniz-Páez et al., 2011, Quintero, 2013). En este sentido, la creación de nuevos productos turísticos coincide con uno de los objetivos de los geoparques de desarrollar una oferta de ocio apoyada en el geoturismo que contribuya a diversificar el turismo y las actividades económicas tradicionales de la isla a través de la creación de empresas locales innovadoras, de nuevos empleos y de cursos formativos altamente cualificados para los diferentes agentes turísticos ${ }^{5}$. Pero a su vez, está en total sintonía con algunos de los objetivos que propone la comisión de geoparques de la International Geographical Union-UGI, relacionados con el papel de estos como herramienta para comunicar, recrear y conservar la naturaleza o para comprender la amplia gama de procesos que afectan el desarrollo sostenible de los geoparques, incluidos el medio ambiente natural, los procesos políticos y socioeconómicos 6 . En este sentido, y en consonancia con lo expresado anteriormente, el objetivo de este estudio es identificar, inventariar, seleccionar y evaluar diferentes geomorfositios de la isla para fomentar el geoturismo como otra de las actividades que se pueden afianzar en El Hierro.

Por tanto, el remarcable patrimonio natural y cultural de El Hierro contribuirá a que desde la administración pública se apueste por la búsqueda de nuevos productos y experiencias geoturísticas que diversifiquen la oferta de ocio en la isla. Asimismo, esta relación de espacios analizados servirá para que, además del geoparque, las empresas de turismo y de ocio alternativo y activo instaladas en la isla cuenten con un estudio para poder implementar sus actividades dotándolas de contenido; estando en consonancia con los objetivos de la red mundial de geoparques y de la comisión de geoparque de la UGI.

\section{Área de estudio}

La isla de El Hierro es la más pequeña, geológicamente más joven y geográficamente más occidental de Canarias. Se encuentra ubicada entre los $27^{\circ} 38^{\prime} 27^{\prime \prime} \mathrm{N}$ y los $17^{\circ} 53^{\prime}$ y $18^{\prime \prime}$ W (Figura No1). La superficie total es de $268,71 \mathrm{~km}^{2}$, lo que supone el 3,61\% del total de Canarias (Istac, 2019) y la altitud máxima está en torno a los 1500 metros en el Pico de Malpaso. El Hierro es de génesis volcánica y se formó a partir de los volcanes-edificios Tiñor (1.12-0.88 Ma), El Golfo-Las Playas (545-176 ka) y el volcanismo de los Rifts (158 ka-actualidad) (Becerril et al., 2015; 2016; Aulinas et al., 2019). Se trata de un conjunto insular volcánicamente activo cuya última erupción ocurrió entre 2011-2012 en el sur de la isla. Los materiales volcánicos que han edificado El Hierro son la sucesión de lavas basálticas, aglomerados de tobas volcánicas y acumulaciones de piroclastos (Carracedo, 2008). La morfología general de la isla es en forma de estrella de tres puntas como consecuencia de las direcciones dominantes de los rifts (Carracedo, 2008). El Hierro es la isla canaria que posee mayor densidad de volcanes; en total cuenta con 230 conos volcánicos que suponen 0,86 conos $/ \mathrm{km}^{2}$ (Becerril et al. 2016). Se trata de volcanes de dinámicas hawaiana, estromboliana, estromboliana violenta, vulcaniana, etc., de morfologías diversas (anulares, abiertos en herradura, múltiples y montañas de piroclastos) (Dóniz-Páez, 2009, 2015) y con emisión de lavas

Disponible en http://www.globalgeopark.org/aboutGGN/51.htm (06/06/2020)

Disponible en http://www.igu-cog.org/vision.htm (06/06/2020) 
dando lugar algunos de los campos lávicos más notables del archipiélago (Beltrán y Dóniz-Páez, 2009). De manera simultánea a los procesos de construcción volcánica, la isla ha estado sometida a los procesos de erosión y acumulación generando paisajes geomorfológicos dominados por este tipo de formas del relieve (El Golfo, La Playas, El Julan, por ejemplo).

El clima de la isla varía según la altitud y las vertientes expuestas a los vientos húmedos (barlovento) y las que no (sotavento). En los sectores de costa hasta los 300 o 400 metros, el clima es cálido-templado con temperaturas medias entre los 19 y $22^{\circ} \mathrm{C}$ y con precipitaciones $<350 \mathrm{~mm} /$ $\mathrm{m}^{2}$ y con más de ocho meses secos al año (Marzol, 2000). Mientras que, en los sectores de mayor altitud, por encima de los $1000 \mathrm{~m}$, es templado-fresco con temperaturas medias entre los 10 y $13^{\circ} \mathrm{C}$ y precipitaciones de $600-1.000 \mathrm{~mm} / \mathrm{m}^{2}$ y con un número de meses secos de 5 a 6 (Marzol, 2000). Entre los 400 y 1000 metros el clima es templado con temperaturas entre los 13 y $16^{\circ} \mathrm{C}$, con precipitaciones entre $<350-600 \mathrm{~mm} / \mathrm{m}^{2}$ y con más de ocho meses secos (Marzol, 2000). Si bien es cierto que existen algunas variaciones de temperatura y precipitaciones entre las vertientes de barlovento y sotavento (Marzol, 2000).

Las condiciones climáticas y la litología volcánica, junto con otros factores como la altitud y la exposición, son responsables del paisaje vegetal de la isla. Este es diverso y comprende matorrales xerófilos abiertos en la costa; bosques esclerófilos termófilos dominados por sabinares (Juniperus phoenicea) junto a bosques de laurisilva y fayal brezal (Ilex canariensis, Visnea mocanera, Picconia excelsa, Erica arbórea, Myrica faya, etc.) y bosques de pinos (Pinus canariensis), que además de estas cotas, ocupan las cumbres de esta pequeña isla (Fernández-Pello, 1989; Del Arco et al., 2006).

Figura No1

Localización de la isla de El Hierro

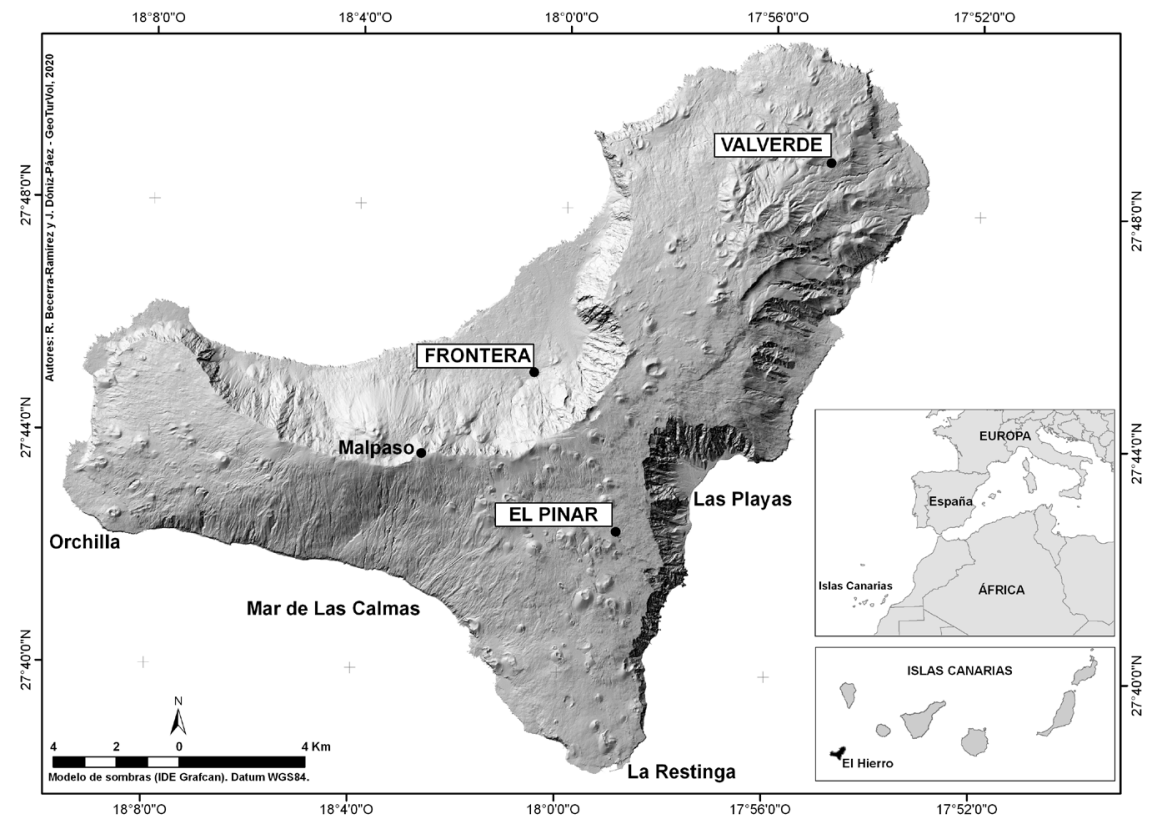

Fuente: Elaboración propia. 
El Hierro es la isla menos poblada de Canarias con tan solo 10.968 habitantes (Istac, 2020) distribuidos en tres municipios (Valverde, La Frontera y El Pinar), en donde la fragmentación ocupacional es una de sus señas de identidad. Las actividades económicas principales son la agricultura, la ganadería y el turismo. El paisaje agrario herreño es bastante variado y destacan el policultivo de secano, los cultivos de plantación de plátano y piña tropical y la ganadería ovina y bovina. En cuanto al turismo, este se dedica fundamentalmente al senderismo y al buceo en la reserva marina del Mar de Las Calmas (De la Cruz-Modino, 2008). Sin duda, estos aspectos condicionan el perfil del turista que visita la isla, caracterizado por su compromiso con la sostenibilidad y por la búsqueda de destinos menos congestionados y de carácter activo y natural. Según los datos aportados por el Cabildo de El Hierro, en el año 2019 visitaron la isla 9028 turistas que suponen tan solo el $0,07 \%$ del total de los que vinieron a Canarias 7 . La mayoría de los turistas son nacionales $(40,2 \%)$, seguidos de alemanes $(27,5 \%)$ y holandeses (7,3\%). Estos tres grupos acogen el $75 \%$ de los visitantes, seguidos de otros del centro y norte de Europa que suman el $25 \%$ restante. La estancia media en El Hierro fue de 13,84, casi cuatro días más que la estancia media en Canarias. Esto, unido a la reducida extensión de la isla, permite a los visitantes conocer con cierta profundidad los diferentes atractivos del geoparque. En este sentido, las principales motivaciones para elegir la isla fueron los paisajes (82,6\%), la tranquilidad $(77,1 \%)$ y el entorno ambiental $(65,4 \%)$, mientras que las playas representan un porcentaje mucho menor $(11,8 \%)$.

La diversidad natural y cultural de la isla y la escasa presión humana son responsables de que El Hierro cuente con siete espacios naturales protegidos que suman el 58,1\% de su superficie, también dispone de una de las pocas reservas marinas de España (1996), es en su totalidad Reserva Mundial de la Biosfera (2000) y Geoparque Mundial de la UNESCO (2014) y tiene previsto contar con el primer parque nacional totalmente marino del país. A todo esto, se suma su apuesta decisiva por la autosuficiencia energética de manera sostenible. En definitiva, todas estas características contribuyen a que en varias ocasiones El Hierro haya sido seleccionado como destino turístico de interés por la prestigiosa National Geographic ${ }^{8}$.

\section{Material y métodos}

La identificación, inventario, selección y evaluación de los geomorfositios se basó en trabajos previos desarrollados en espacios naturales protegidos (Serrano \& González-Trueba, 2005; González et al., 2014), pero con la introducción de especificidades para espacios volcánicos (Becerra-Ramírez, 2013; Pérez-Umaña et al., 2019). El trabajo se desarrolló en varias fases: 1- identificación, inventario y selección de los geomorfositos; 2- documentación de los lugares y 3- evaluación de los geomorfositios a través del cálculo del geopatrimonio teniendo en cuenta sus valores intrínsecos o científicos, añadidos y de uso y gestión (Serrano \& González-Trueba, 2005; Becerra-Ramírez, 2013; González et al., 2014; Serrano et al., 2018). 


\section{Identificación, inventario y selección de los geomorfositios}

La identificación de los geomorfositios se realizó sobre cartografía topográfica, geológica y geomorfológica a diferentes escalas (1.1000, 1:5000 y 1:2500), sobre modelos digitales del terreno del IDE-canarias y Grafcan y el trabajo de campo durante las campañas de octubre de 2018, enero y agosto de 2019. El inventario de los geomorfositios se ha desarrollado en tres etapas. En la primera se clasificaron las formas de relieve en dos bloques, por un lado, aquellas que están agrupadas -"lugares"-, y por otro, las consideradas de manera individual -"elementos"-. Para cada bloque se determinó su singularidad (entendida como "cualidad única" en el conjunto de morfologías locales), o su representatividad (aquellas formas de relieve que destacan del resto gracias a sus valores intrínsecos, añadidos o de uso y gestión). Por tanto, para cada geomorfositio inventariado se indica si corresponde a un elemento singular (ES), a un lugar singular (LS), a un elemento representativo (ER) o a un lugar representativo (LR), del mismo modo que lo que han propuesto otros autores (González-Trueba y Serrano, 2008; González et al., 2014). Además, también se señala si los geomorfositios corresponden a morfologías volcánicas directas (conos volcánicos, cráteres, campos de lavas, tubos volcánicos, plataformas lávicas, etc.), a formas de erosión y acumulación (barrancos, acantilados, playas, dunas, etc.) o son fruto de ambos. En la segunda etapa se identificaron los geomorfositios, atendiendo a su conservación, accesibilidad y visibilidad (Mikhailenko \& Ruban, 2019). Si bien es cierto que, en algunos casos como el volcán submarino, este último requisito no lo cumple, su interés geoturístico queda demostrado con las visitas e inmersiones en la zona en donde tuvo lugar la erupción volcánica. Y en la tercera etapa, se seleccionan los geomorfositios teniendo en cuenta que las formas elegidas son representativas de la diversidad geomorfológica del geoparque de El Hierro.

\section{Documentación de los geomorfositios}

La documentación incluyó dos tipos de datos. Por un lado, datos numéricos generales (coordenadas, elevación, por ejemplo) que permiten ubicar el geomorfositio en un mapa de síntesis como el de la figura $\mathrm{N}^{\circ} 2$ y $\mathrm{N}^{\circ} 5$. Y, por otro, información cualitativa sobre la caracterización de estos (geología, geomorfología, geografía, historia). Este segundo paso es clave para la evaluación de cada uno de los ítems que se tienen en cuenta en la evaluación geopatrimonial. Ambos tipos de datos se recogieron en una ficha que facilita el tratamiento de la información.

\section{Evaluación geopatrimonial}

Los valores científicos o intrínsecos se refieren a las características propias e inherentes del geomorfositio. Estos valores reflejan la variedad de formas y procesos dominantes del lugar seleccionado. Se ha tendido en cuenta la variedad y no el número (Serrano \& González-Trueba, 2005). Se considera: 1-morfoestructuras (litológicas y tectónicas), 2-diversidad de otros elementos de interés geológico (tectónicos, estratigráficos, paleontológicos, mineralógicos, petrológicos, hidrogeológicos), 3-morfología (formas erosivas y de acumulación) y 4-dinámica (heredada y funcional) (Cuadro No1). La puntuación máxima obtenida es de 10 para cada uno de los ítems excepto para la diversidad de otros elementos de interés geológico que es de 5. La puntuación total máxima obtenida es de 45. 
Cuadro No 1

Evaluación de los valores científicos según González et al., 2014

\begin{tabular}{|l|c|c|}
\hline İtems científicos & & Valores \\
\hline \multirow{2}{*}{ Morfoestructuras } & Litología & Máximo 5 \\
\cline { 2 - 3 } & Tectónica & Máximo 5 \\
\hline Diversidad & & Máximo 5 \\
\hline \multirow{2}{*}{ Morfología } & Formas de erosión & Máximo 10 \\
\hline \multirow{2}{*}{ Dinámica } & Formas de acumulación & Máximo 10 \\
\cline { 2 - 3 } & Heredada & Máximo 5 \\
\cline { 2 - 3 } & Funcionales & Máximo 5 \\
\hline
\end{tabular}

Fuente: Adaptado de González et al., 2014: 49

Los añadidos se refieren a aquellos valores culturales y ambientales que condicionan y enriquecen a los científicos y que están muy directamente relacionados con la actividad humana. Se consideran: 1-valoración paisajística y estética, 2-elementos culturales (patrimonio e histórico-cultural), 3-elementos didácticos (pedagogía y asociación con otros elementos del medio natural), 4-elementos científicos (áreas de conocimiento e información aportada) y 5-contenido turístico (reales y atracción) (Cuadro $\mathrm{N}^{\circ} 2$ ). La puntuación máxima obtenida para cada ítem es de 10, excepto para los valores paisajísticos y estéticos que es de 20. La puntuación total máxima obtenida es de 60.

\section{Cuadro $\mathrm{N}^{\circ} 2$}

Evaluación de los valores añadidos según González et al., 2014

\begin{tabular}{|c|c|c|}
\hline tems & & Valores \\
\hline $\begin{array}{l}\text { Valoración } \\
\text { paisajística }\end{array}$ & $\begin{array}{l}\text { Valoración paisajística y estética: No existe (0), Componente muy local } \\
\text { y puntual. Componente a escala media (valle, municipio). Componen- } \\
\text { te comarcal. Componente esencial del paisaje en amplios panoramas } \\
\text { (regional). Elemento protegido o gestionado por sus contenidos pai- } \\
\text { sajísticos (20) }\end{array}$ & Máximo 20 \\
\hline \multirow{2}{*}{$\begin{array}{l}\text { Elementos } \\
\text { culturales }\end{array}$} & Asociación elementos de valor patrimonial & Máximo 5 \\
\hline & Contenido histórico-cultural (1-5) & Máximo 5 \\
\hline \multirow{2}{*}{$\begin{array}{l}\text { Elementos } \\
\text { didácticos }\end{array}$} & Valor como recurso pedagógico (1-5) & Máximo 5 \\
\hline & \begin{tabular}{|l|} 
Asociación con otros elementos naturales \\
\end{tabular} & Máximo 5 \\
\hline \multirow{2}{*}{$\begin{array}{l}\text { Elementos } \\
\text { científicos }\end{array}$} & Áreas de conocimiento (1-5) & Máximo 5 \\
\hline & $\begin{array}{l}\text { Información que aporta a la reconstrucción de la evolución geomor- } \\
\text { fológico (1-5) }\end{array}$ & Máximo 5 \\
\hline \multirow{2}{*}{$\begin{array}{l}\text { Contenido } \\
\text { turístico }\end{array}$} & Contenido turístico: histórico, artístico, paisajístico, otros (1-5) & Máximo 5 \\
\hline & Atracción turística: internacional, nacional, local (1-5) & Máximo 5 \\
\hline
\end{tabular}

Fuente: Adaptado de González et al., 2014: 50

Los valores de uso y gestión se reparten entre: 1-fragilidad/riesgo de degradación (accesibilidad -10 puntos-, frecuentación -10 puntos-, fragilidad intrínseca - 5 puntos-, fragilidad externa -5 puntos-, tipo e intensidad del uso -5 puntos- e impacto -5 puntos-) y 2 -potencialidad de uso (va- 
lor intrínseco -15 puntos-, valor añadido -15 puntos-, significación paisajística - 5 puntos-, estado de conservación - 5 puntos-, accesibilidad -10 puntos- y condiciones de observación -5 puntos-) (Cuadro N³). La puntuación total máxima obtenida es de 95.

\section{Cuadro No3}

Evaluación de los valores de uso y gestión según González et al., 2014

\begin{tabular}{|c|c|c|}
\hline Ítems & & Valores \\
\hline \multirow{6}{*}{$\begin{array}{l}\text { Fragilidad y riesgo de } \\
\text { degradación }\end{array}$} & Accesibilidad: (1 Muy baja - 5 Muy alta)*2 & Máximo 10 \\
\hline & Frecuentación: (1 Muy baja - 5 Muy alta )*2 & Máximo 10 \\
\hline & Fragilidad intrínseca: 1 Muy baja - 5 Muy alta & Máximo 5 \\
\hline & Fragilidad externa/amenazas: 1 Muy baja - 5 Muy alta & Máximo 5 \\
\hline & Tipo e intensidad del uso: (1 Muy baja - 5 Muy alta) & Máximo 5 \\
\hline & Impacto: (1 Muy baja - 5 Muy alta) & Máximo 5 \\
\hline \multirow{6}{*}{ Potencialidad de uso } & Valor intrínseco: $(1-5)^{\star} 3$ & Máximo 15 \\
\hline & Valor añadido: $(1-5)^{*} 3$ & Máximo 15 \\
\hline & Significación paisajística: (1-5) & Máximo 5 \\
\hline & Estado de conservación: (1-5) & Máximo 5 \\
\hline & Accesibilidad: $(1-5)^{\star} 2$ & Máximo 10 \\
\hline & Condiciones de observación: (1-5) & Máximo 5 \\
\hline
\end{tabular}

Fuente: Adaptado de González et al., 2014: 51

Para poder establecer comparaciones entre los tres tipos de valores estos se expresan con puntuaciones ponderadas de 1 a 5 . Se ha establecido una escala en la que se considera un valor bajo, cuando este es $<1,5$, medio cuando es $\geq 1,5$ y $\leq 3$, y alto para los valores $>3$ (González et al., 2014).

\section{Resultados y discusión}

\section{Inventario y caracterización de los geomorfositios}

Se han inventariado, seleccionado y caracterizado un total de 20 geomorfositios asociados a la diversidad de geoformas del geoparque (Figura No2). La isla de El Hierro es de origen volcánico y sus rasgos geomorfológicos actuales son resultado de la combinación de procesos generados directamente durante las sucesivas erupciones acaecidas en la isla y los de erosión y acumulación. Unos y otros son los que dan lugar a la geodiversidad en la isla, similar a la que se ha reconocido en otros paisajes volcánicos repartidos por diferentes geografías del mundo (Gao et al., 2014; Lima et al., 2014; Németh \& Moufti, 2017; Németh et al., 2017; Zangmo-Tefogoum et al., 2017; Megerssa et al., 2019, Turoğlu 2020).

El volcanismo basáltico monogénico ha dado lugar a 230 conos volcánicos de morfología diversa (cerrados-anulares, abiertos en herradura, múltiples, montañas de lapilli) y a numerosos coneletes escoriáceos y hornitos construidos por piroclastos (bombas, escorias, lapilli y cenizas), spatter y algunas lavas interestratificadas. Desde los cráteres y fisuras eruptivas de estos edificios 
volcánicos se emitieron coladas de lava con morfologías superficiales variadas (pahoehoe, aa, en bloques con bolas de acreción, etc.) en las que se puede reconocer una amplia gama de formas mayores y menores: tubos volcánicos, jameos, túmulos, canales de lava, muros laterales de enfriamiento, represamientos lávicos, cascadas de lava, taludes lávicos, bolas de acreción, basaltos columnares, arcos de empuje, etc. Al mismo tiempo, no podemos obviar la presencia del volcanismo félsico de tipo explosivo en la isla. Este es poco representativo y está asociado a depósitos de pumitas en los alrededores de Malpaso (Pedrazzi et al., 2014).

\section{Figura $\mathrm{N}^{0} 2$}

Esquema geomorfológico y geomorfositios del geoparque de El Hierro

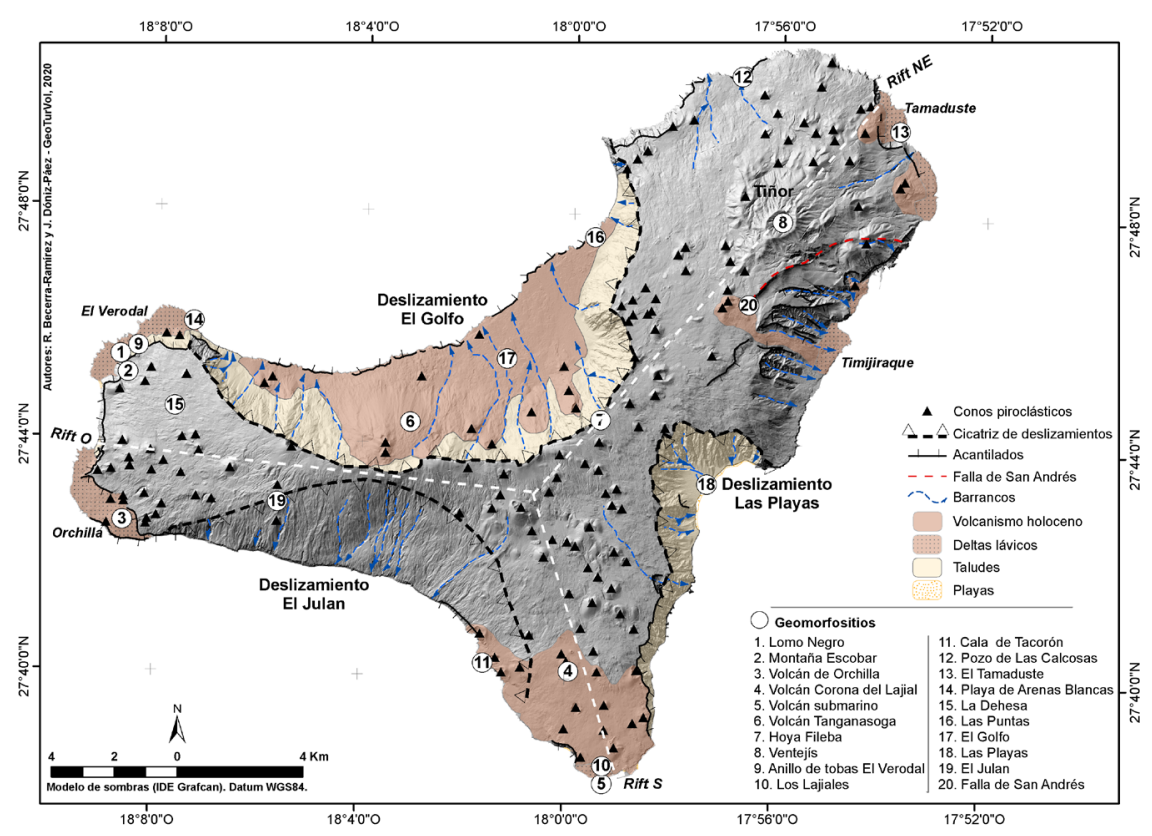

Las formas y procesos asociados a la erosión y acumulación están protagonizados por los grandes deslizamientos gravitacionales que dieron lugar a la formación de Tiñor, El Golfo, Las Playas y El Julan (Carracedo, 2008). Sin embargo, también están presentes los vinculados con los procesos torrenciales con la formación de barrancos e importantes abanicos aluviales; los de dinámica marina con sus acantilados fósiles y activos y las playas de arenas y cantos; también se reconocen los asociados con la dinámica de vertiente y la formación de coluviones, y los eólicos con la presencia de pequeños campos de dunas tipo nebkas (Playa Blanca).

En el cuadro $\mathrm{N}^{\circ} 4$ se muestra el tipo de geomorfositio, si están incluidos o no en espacios naturales protegidos, así como las formas del relieve dominantes en cada uno de ellos. Como se observa, los cuatro tipos de espacios y lugares definidos (ES, ER, LS y LR) se pueden reconocer en los veinte geomorfositios seleccionados, repartidos al $50 \%$ entre los elementos y los lugares (Figura No3). Los elementos singulares corresponden con geoformas características de la isla como los volcanes basálticos monogénicos (Lomo Negro, Corona del Lajial), los restos de un volcán hidromagmático (anillo de Tobas), elementos tectónicos (falla de San Andrés) o una pla- 
ya de arenas organógenas única en El Hierro. Los elementos representativos hacen referencia a conjuntos eruptivos muy singulares del geoparque, como la erupción fisural de casi un kilómetro de Montaña Escobar, el cráter freatomagmático de Hoya Fileba con más de $0.5 \mathrm{~km}$ de diámetro y unos 140 metros de profundidad y el volcán hidromagmático de Ventejís que corresponde con el cono volcánico de mayor envergadura de la isla con un diámetro mayor y menor del cráter de 1 y 0.9 kilómetros respectivamente. Los lugares singulares hacen referencia a los geomorfositios que ocupan una mayor superficie en la isla (El Golfo, El Julan, Las Playas, Las Puntas o La Dehesa) y que albergan una gran diversidad de geoformas. Mientras que los lugares representativos acogen a aquellos de menor extensión, pero que destacan por el carácter reciente de su volcanismo y su ubicación litoral, generando magníficos ejemplos de plataformas o deltas lávicos que saltaron cantiles previos fosilizándolos y ampliando la superficie insular (Figura $\mathrm{N}^{\circ} 4$ ).

\section{Cuadro $\mathrm{N}^{\circ} 4$}

Caracterización de los geomorfositios en función de las formas dominantes

\begin{tabular}{|c|c|c|c|c|}
\hline $\mathrm{N}^{\circ}$ & $\begin{array}{c}\text { Nombre } \\
\text { geomorfositio }\end{array}$ & Tipo & Protegido & Formas del relieve \\
\hline 1 & Lomo Negro & ES & Si & $\begin{array}{l}\text { Cono volcánico, hornitos, campo lavas, tubos volcáni- } \\
\text { cos, acantilados activos y fósiles, abanicos aluviales, } \\
\text { coluviones }\end{array}$ \\
\hline 2 & $\begin{array}{l}\text { Montaña } \\
\text { Escobar }\end{array}$ & ER & Si & $\begin{array}{c}\text { Cono volcánico, hornitos, campo lavas, tubo volcánico, } \\
\text { erupción fisural, cantil, barrancos }\end{array}$ \\
\hline 3 & $\begin{array}{l}\text { Volcán de } \\
\text { Orchilla }\end{array}$ & LR & Si & $\begin{array}{c}\text { Cono volcánico, coneletes escoriáceos, hornitos, lavas, } \\
\text { plataformas lávicas, tubos volcánicos, acantilados, } \\
\text { barrancos, aluviones, coluviones }\end{array}$ \\
\hline 4 & $\begin{array}{c}\text { Volcán Corona } \\
\text { del Lajial }\end{array}$ & ES & Si & $\begin{array}{l}\text { Cono volcánico, coneletes escoriáceos, hornitos, cam- } \\
\text { po lavas, tubos volcánicos, cascadas de lava, hundi- } \\
\text { mientos, coluviones }\end{array}$ \\
\hline 5 & $\begin{array}{c}\text { Volcán } \\
\text { submarino }\end{array}$ & ES & $\mathrm{Si}$ & Cono volcánico erupción 2011-2012 \\
\hline 6 & $\begin{array}{c}\text { Volcán } \\
\text { Tanganasoga } \\
\end{array}$ & ER & Si & $\begin{array}{c}\text { Conos volcánicos, freatomagmatismo, cráteres, cam- } \\
\text { pos de lava, barrancos, taludes de gravedad }\end{array}$ \\
\hline 7 & Hoya Fileba & ER & Si & $\begin{array}{c}\text { Cono volcánico freático, cráter, barrancos, coluviones, } \\
\text { aluviones }\end{array}$ \\
\hline 8 & Ventejís & ER & Si & $\begin{array}{l}\text { Cono volcánico, cráter, barrancos, coluviones, aluvio- } \\
\text { nes }\end{array}$ \\
\hline 9 & $\begin{array}{c}\text { Anillo de Tobas } \\
\text { Verodal }\end{array}$ & ES & Si & $\begin{array}{l}\text { Restos cono volcánico hidromagmático, barrancos, } \\
\text { cantil fósil, coluviones, aluviones }\end{array}$ \\
\hline 10 & Los Lajiales & LR & Si & $\begin{array}{c}\text { Lavas pahoehoe y aa, cascadas de lava, conos volcá- } \\
\text { nicos, tubos volcánicos, canales de lava, barrancos, } \\
\text { cantil, playas }\end{array}$ \\
\hline 11 & Cala Tacorón & LR & No & $\begin{array}{l}\text { Delta lávico, cono volcánico, cantil, plataforma abra- } \\
\text { sión, playas }\end{array}$ \\
\hline 12 & Pozo Calcosas & LR & No & $\begin{array}{l}\text { Delta lávico, cantil activo y fósil, plataforma abrasión, } \\
\text { playas }\end{array}$ \\
\hline 13 & El Tamaduste & LR & No & $\begin{array}{l}\text { Lavas aa, bolas acreción, basaltos columnares, taludes } \\
\text { lávicos, barrancos, cantil fósil y activo, playas, aluvio- } \\
\text { nes, coluviones }\end{array}$ \\
\hline
\end{tabular}




\begin{tabular}{|c|c|c|c|c|}
\hline No & $\begin{array}{c}\text { Nombre } \\
\text { geomorfositio }\end{array}$ & Tipo & Protegido & Formas del relieve \\
\hline 14 & Playa Blanca & ES & Si & $\begin{array}{r}\text { Lavas, playa de arenas organógenas, dunas, cantil fósil } \\
\text { y activo, plataforma marina, aluviones }\end{array}$ \\
\hline 15 & La Dehesa & LS & Si & $\begin{array}{r}\text { Campo volcánico, conos volcánicos, lavas, barrancos, } \\
\text { taludes detríticos }\end{array}$ \\
\hline 16 & Las Puntas & LS & No & $\begin{array}{r}\text { Plataforma lávica, coneletes escoriáceos, hornitos, ba- } \\
\text { saltos columnares, tubos volcánicos, cantil, barrancos, } \\
\text { aluviones, coluviones, playas }\end{array}$ \\
\hline 17 & El Golfo & LS & Si & $\begin{array}{r}\text { Conos volcánicos, coladas de lavas, deslizamientos, } \\
\text { barrancos, cantiles, aluviones, coluviones, playas }\end{array}$ \\
\hline 18 & Las Playas & LS & Si & $\begin{array}{r}\text { Deslizamientos, barrancos, cantiles, taludes de grave- } \\
\text { dad, abanicos aluviales, playas }\end{array}$ \\
\hline 19 & El Julan & LS & Si & $\begin{array}{r}\text { Coladas de lavas, deslizamientos, barrancos, cantiles, } \\
\text { taludes de gravedad }\end{array}$ \\
\hline 20 & $\begin{array}{c}\text { Falla San } \\
\text { Andrés }\end{array}$ & ES & No & Falla, barranco, taludes de gravedad \\
\hline
\end{tabular}

Fuente: elaboración propia basada en datos de campo y cartografía geomorfológica

Figura $\mathrm{N}^{\circ} 3$

Distribución porcentual de los lugares representativos (LR), lugares singulares (LS), elementos representativos (ER) y elementos singulares (ES) en los geomorfositios seleccionados del geoparque de El Hierro

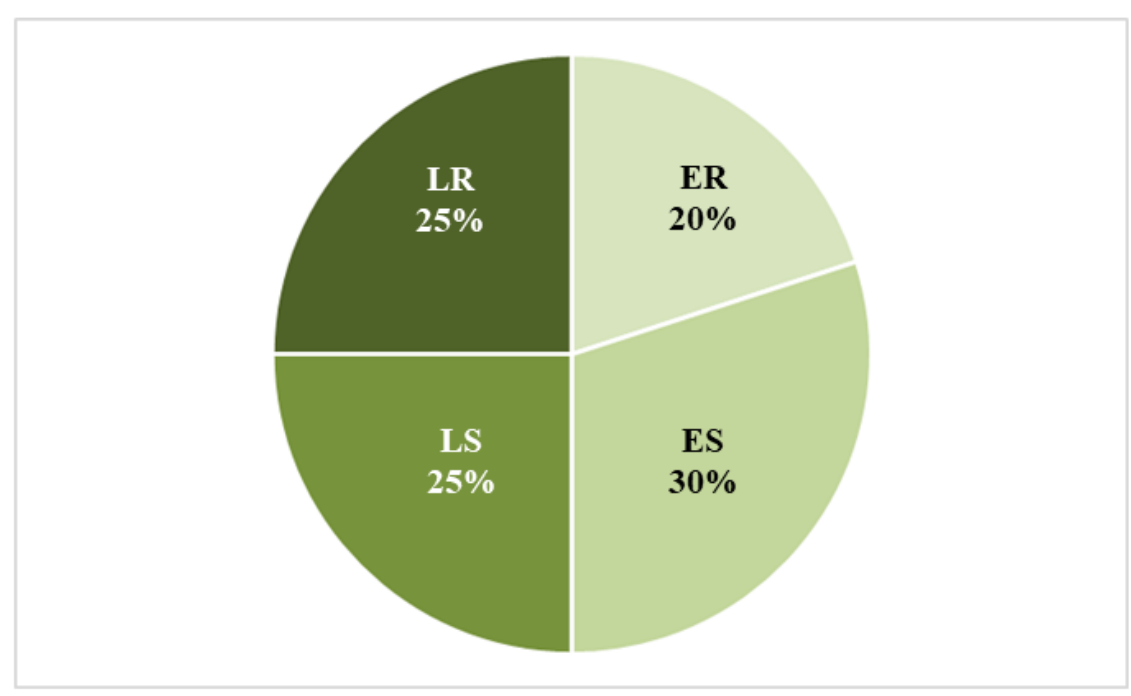

Fuente: elaboración propia basada en datos del cuadro n 4 
Figura $\mathrm{N}^{\circ} 4$

Ejemplo de algunos geomorfositios seleccionados. Volcanes monogénicos múltiples de Lomo Negro (a), Orchilla (b) y Montaña Escobar (c). Deslizamiento de Las Playas (d). Delta lávico aa y cono volcánico acantilado de Tacorón (e). Playa de arenas organógenas de Arenas Blancas (f) volcán monogénico múltiple y lavas de Tanganasoga (g). Cascadas y columnas lávicas pahoehoe de Los Lajiales (h) y acantilados de Las Puntas (i)
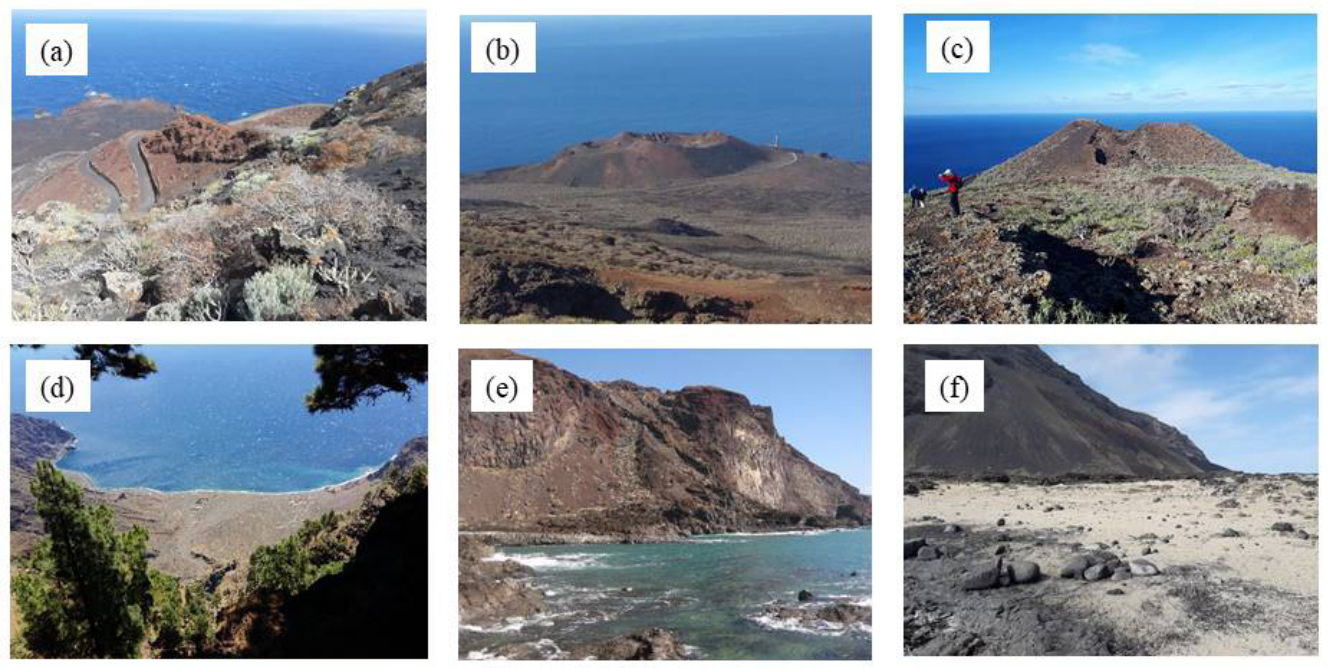

(g)
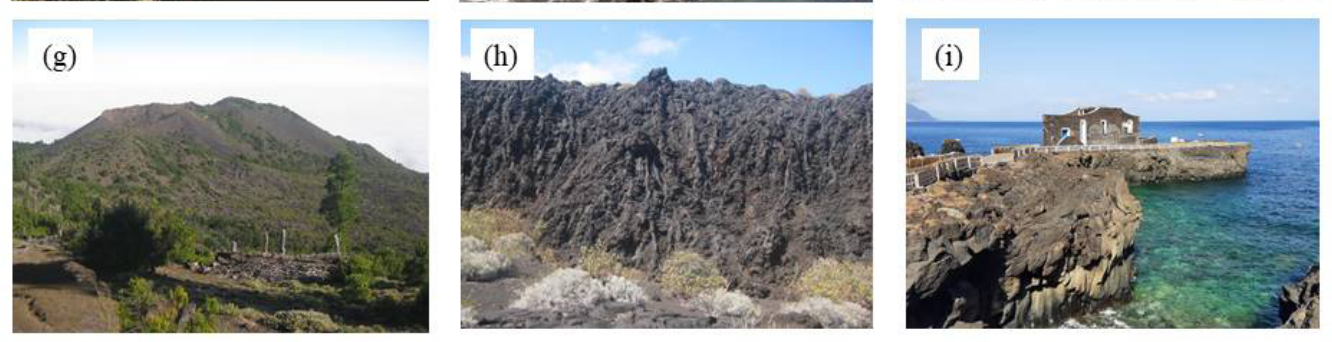

Fuente: archivo de autores.

La figura N05 muestra la localización espacial de los 20 geomorfositios seleccionados de El Hierro y su relación con la red de carreteras principales del geoparque y con los espacios naturales protegidos de la isla. Aunque las formas del relieve están presentes en cada una de las diferentes categorías de espacios naturales protegidos definidas para la isla, es en el monumento natural, el parque rural y algunas reservas donde la gea es más significativa. Como se puede apreciar en la figura N05, todos los geomorfositios tienen acceso por carretera a excepción del volcán submarino, lo que facilita que los visitantes puedan llegar hasta ellos. El 75\% de los geomorfositios está dentro de un espacio natural protegido y el $25 \%$ restante quedan fuera de estos aun mostrando rasgos geomorfológicos bien conservados (Tacorón, Calcosas, falla de San Andrés, Tamaduste y Las Puntas). De los espacios naturales protegidos destacan el Parque Rural de Frontera que alberga el 50\% de los geomorfositios seleccionados y las Reservas Naturales Integrales de Mencáfete y Roques de Salmor que no cuentan con ninguno de ellos. Esto último está relacionado con que la accesibilidad a las mismas es muy escasa o inexistente y que la legislación canaria de ENP no permite el uso turístico dentro de las reservas naturales integrales. 
Figura No 5

Localización espacial de los veinte geomorfositios estudiados en este trabajo y su relación con los espacios naturales protegidos de la isla y su accesibilidad

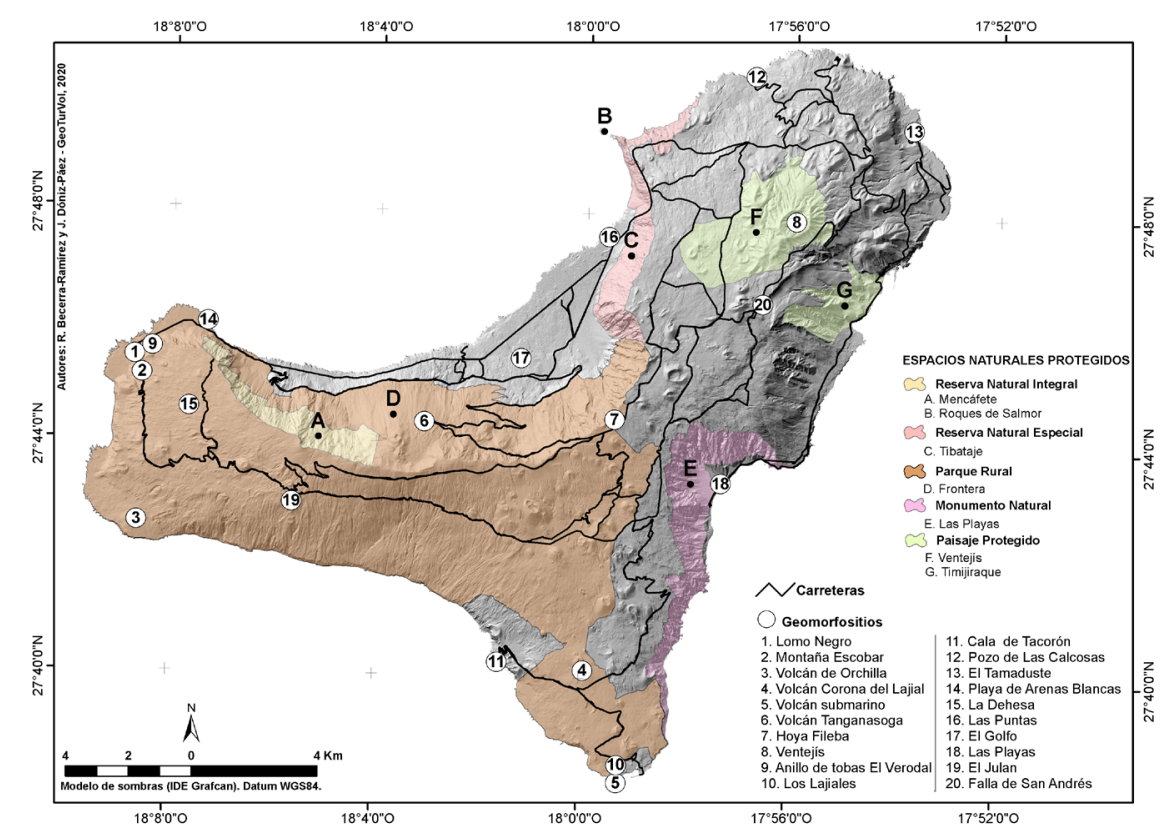

Fuente: IDE-canarias. Elaboración propia

\section{Evaluación geopatrimonial de los geomorfositios}

El cuadro $\mathrm{N}^{0} 5$ recoge las puntuaciones ponderadas obtenidas para cada geomorfositio tras aplicar la evaluación del geopatrimonio. Estas aparecen desglosadas en valores científicos, añadidos y de uso y gestión, la puntuación media y la escala de cada geomorfositio. En líneas generales, la media de los valores individuales más altos corresponde al ítem de uso y gestión (2.5), seguido del científico o intrínseco (2.3) y el añadido (2.2). El 60\% de los geomorfositios herreños poseen índices medios, seguido del $30 \%$ que son altos y el $10 \%$ bajos. La figura $N^{\circ} 6$ muestra el desglose de cada índice según valores altos, medios y bajos, apreciándose un predominio de los valores medios para los tres tipos de ítems. Los datos anteriores no son sorprendentes, puesto que, aunque los geomorfositios seleccionados son los lugares más representativos de la geodiversidad de El Hierro, la isla es totalmente de origen eruptivo y se caracteriza por un volcanismo fundamentalmente basáltico y de edad reciente. Estas tres razones son la causa de que la diversidad de formas y procesos sea menor que si estuviéramos aplicando esta misma valoración a lugares con intervención de fenómenos eruptivos diversos (basáltico, sálico, etc.), con variados procesos genéticos (volcanismo, kárstico, granítico, fluvial, glaciar, etc.) y a lo largo de periodos geológicos distintos que permitiesen recoger cronologías variadas o formas y procesos heredados, como suceden con otros lugares en donde se han aplicado metodologías de este tipo o similares (Riso et al., 2006; Becerra-Ramírez, 2013; González et al., 2014; Henriques \& Neto, 2015; Bouzekraoui et al., 2017; Serrano et al., 2018; Pérez-Umaña et al., 2019; 2020; Quesada-Román \& Pérez-Umaña, 2020). 


\section{Cuadro N05}

Valoración de los geomorfositios

\begin{tabular}{|c|c|c|c|c|c|c|}
\hline No & Geomorfositio & Científicos & Añadidos & Uso y gestión & Media & Escala \\
\hline 1 & Lomo Negro & 2 & 1.3 & 2.3 & 1.9 & Medio \\
\hline 2 & Montaña Escobar & 2.4 & 1.7 & 2.5 & 2.2 & Medio \\
\hline 3 & Volcán Orchilla & 2.7 & 2.8 & 3.4 & 3 & Alto \\
\hline 4 & Volcán Corona Lajial & 2.6 & 2.3 & 2.4 & 2.4 & Medio \\
\hline 5 & Volcán submarino & 1.3 & 0.8 & 1.4 & 1.2 & Bajo \\
\hline 6 & Volcán Tanganasoga & 2 & 2.1 & 2.2 & 2.1 & Medio \\
\hline 7 & Hoya Fileba & 1.7 & 1.7 & 2 & 1.8 & Medio \\
\hline 8 & Ventejís & 1.7 & 2.1 & 2.4 & 2 & Medio \\
\hline 9 & Anillo Tobas Verodal & 1.4 & 1.4 & 1.7 & 1.5 & Medio \\
\hline 10 & Los Lajiales & 3.3 & 2.7 & 3.3 & 3.1 & Alto \\
\hline 11 & Cala Tacorón & 2.3 & 2.3 & 2.9 & 2.5 & Medio \\
\hline 12 & Pozo Calcosas & 2 & 2.2 & 2.4 & 2.2 & Medio \\
\hline 13 & El Tamaduste & 2.7 & 2.4 & 2.9 & 2.7 & Medio \\
\hline 14 & Playa Blanca & 2.1 & 2.2 & 2.1 & 2.1 & Medio \\
\hline 15 & La Dehesa & 2.9 & 3.2 & 3 & 3 & Alto \\
\hline 16 & Las Puntas & 2.1 & 2.8 & 3 & 2.6 & Medio \\
\hline 17 & El Golfo & 3.1 & 3.4 & 3.7 & 3.4 & Alto \\
\hline 18 & Las Playas & 2.8 & 3 & 3.2 & 3 & Alto \\
\hline 19 & Julan & 2.9 & 3.5 & 2.5 & 3 & Alto \\
\hline 20 & Falla San Andrés & 1.3 & 1 & 1.4 & 1.3 & Bajo \\
\hline
\end{tabular}

Fuente: elaboración propia basada en datos geográficos, geológicos, geomorfológicos, paisajísticos, culturales, etc.

\section{Figura $\mathrm{N}^{\circ} 6$}

Porcentajes altos, medios y bajos para cada tipo de valores (científico, añadido y de uso y gestión) de los veinte geomorfositios de El Geoparque Mundial Unesco de El Hierro

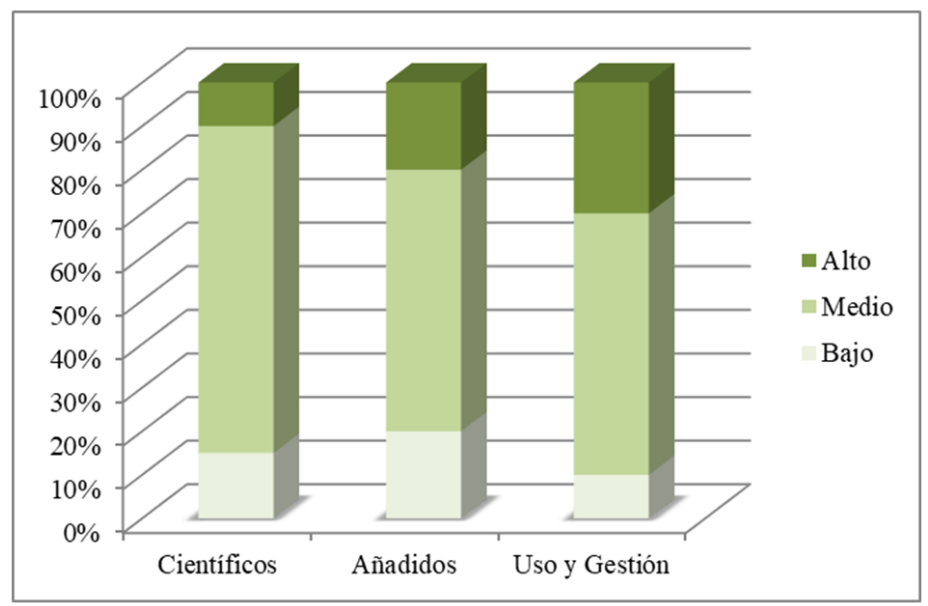

Fuente: elaboración propia basada en datos del cuadro nº 5. 
El geomorfositio con los índices más altos para los tres tipos de valores es El Golfo, pero el que cuenta con la puntuación más alta para los valores científicos es Los Lajiales, seguido de EI Golfo, El Julan, La Dehesa, Las Playas y los volcanes de Orchilla y La Corona del Lajial (Figura $N^{\circ} 7$ ). Prácticamente estas mismas puntuaciones altas se repiten para estos geomorfositios en las otras dos valoraciones. Estos datos se pueden explicar por dos razones fundamentales. Por un lado, parece existir una correlación entre la extensión de los geomorfositios, la diversidad de formas y procesos, y la variedad de usos antrópicos que favorece la obtención de índices de valoración altos (El Golfo, El Julan, La Dehesa y Las Playas). Y, por otro, que los geomorfositios estudiados (Figura $\mathrm{N}^{\circ} 6$ ) poseen un elevado interés geoturístico en relación a sus elementos geomorfológicos y su accesibilidad, como es el caso de los volcanes de La Corona del Lajial (Dóniz-Páez et al., 2011) y sus lavas Los Lajiales (Beltrán \& Dóniz-Páez, 2009), el conjunto eruptivo de Orchilla y su entorno (Dóniz-Páez et al., 2019c) o el Valle de El Golfo que se trata del paisaje más complejo y variado de la isla de El Hierro (Fernández-Pello, 1986). En el lado opuesto están los geomorfositios de la erupción submarina, la falla de San Andrés y el anillo de tobas de El Verodal que disponen de los

Figura N07

Ejemplo de los valores científicos de los geomorfositios seleccionados. (a) Cono volcánico múltiple de La Corona del Lajial. (b) Cráter hidromagmático de Hoya Fileba. (c) Hornito de spatter de Orchilla. (d) Superposición de lavas pahoehoe y aa de Los Lajiales. (e) Anillo de tobas freatomagmático de La Hoya del Verodal y acantilados con taludes. (f) Espejo de falla de San Andrés. (g) Basaltos columnares del

Tamaduste (h) Deslizamiento del Julan. (i) Deslizamiento y deltas lávicos del Valle de El Golfo
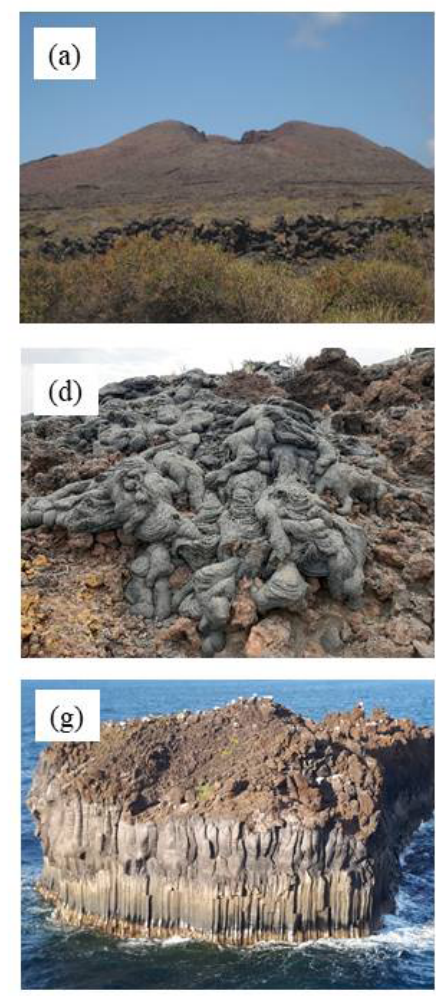
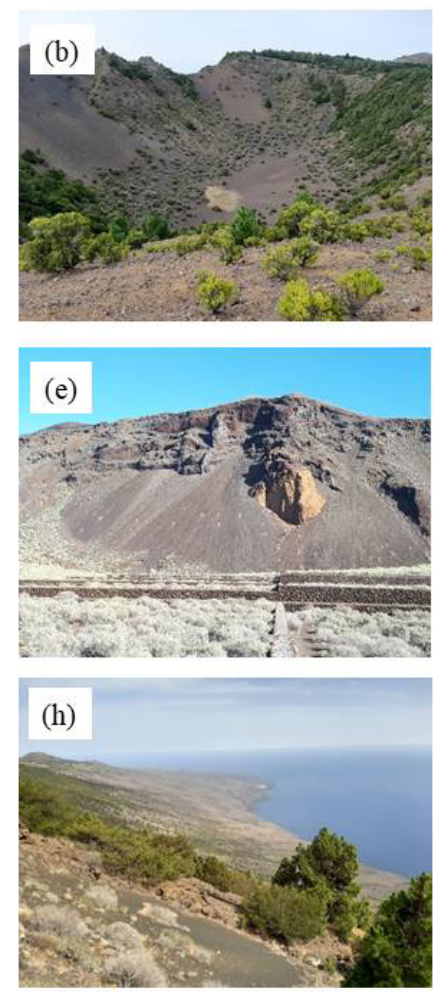
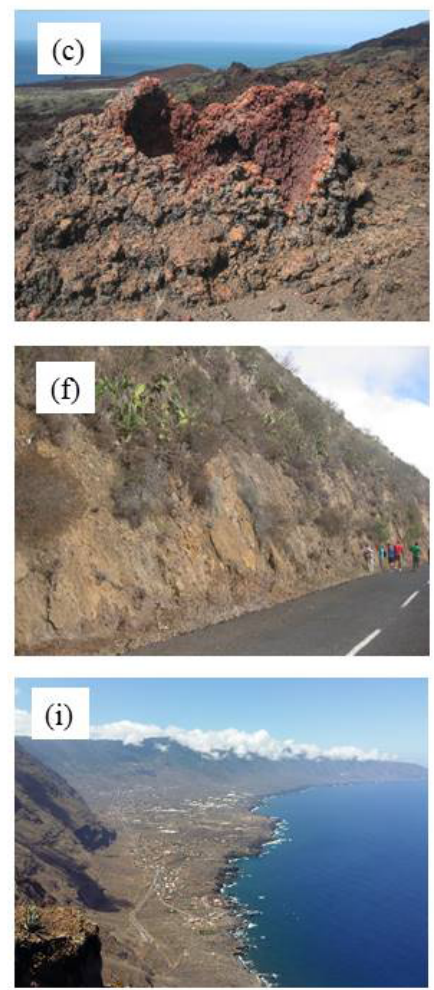

Fuente: archivo de autores. 
índices más bajos. Este hecho se puede relacionar con su escasa superficie y con que no cuentan prácticamente con usos antrópicos. La erupción submarina posee las puntuaciones más bajas para los tres tipos de valores, lo que no es de extrañar puesto que este conjunto eruptivo no llegó nunca a emerger, quedándose tan sólo a 80 metros de la superficie del mar (Carracedo, 2020). Aun así, su interés es indudable tanto por el papel que desempeñó en la decisión de que las autoridades insulares solicitasen que la isla fuese candidata a geoparque, como para el geoturismo en El Hierro, al ubicarse en la reserva marina del Mar de Las Calmas y a menos de $2 \mathrm{~km}$ de La Restinga que es el principal núcleo de turismo de la isla y que mayoritariamente se dedica al buceo.

Los veinte geomorfositios seleccionados y analizados del geoparque herreño tienen en cuenta elementos y valores representativos del patrimonio natural y cultural de la isla (Figura No8). Este aspecto queda reflejado en la metodología empleada para llevar a cabo la valoración geopatrimonial de los geomorfositios, que ha sido aplicada con éxito en otros lugares (Serrano \& González-Trueba, 2005; Becerra-Ramírez, 2013; González et al., 2014; Serrano et al., 2018). Esta manera

\section{Figura No8}

Ejemplo de los valores culturales de los geomorfositios seleccionados. (a) Ganadería en la Dehesa.

(b) Muros de piedra seca Montaña Escobar. (c) Zona arqueológica en Los Lajiales. (d) Lagartario y Ecomuseo de Guinea en El Golfo. (e) Sistema tradicional para recogida del agua de la lluvia en Tacorón. (f) Pueblo tradicional de Las Calcosas. (g) Ermita de los Reyes patrona de la isla (h)

Monumento al meridiano 0 en Orchilla. (i) Faro de Orchilla
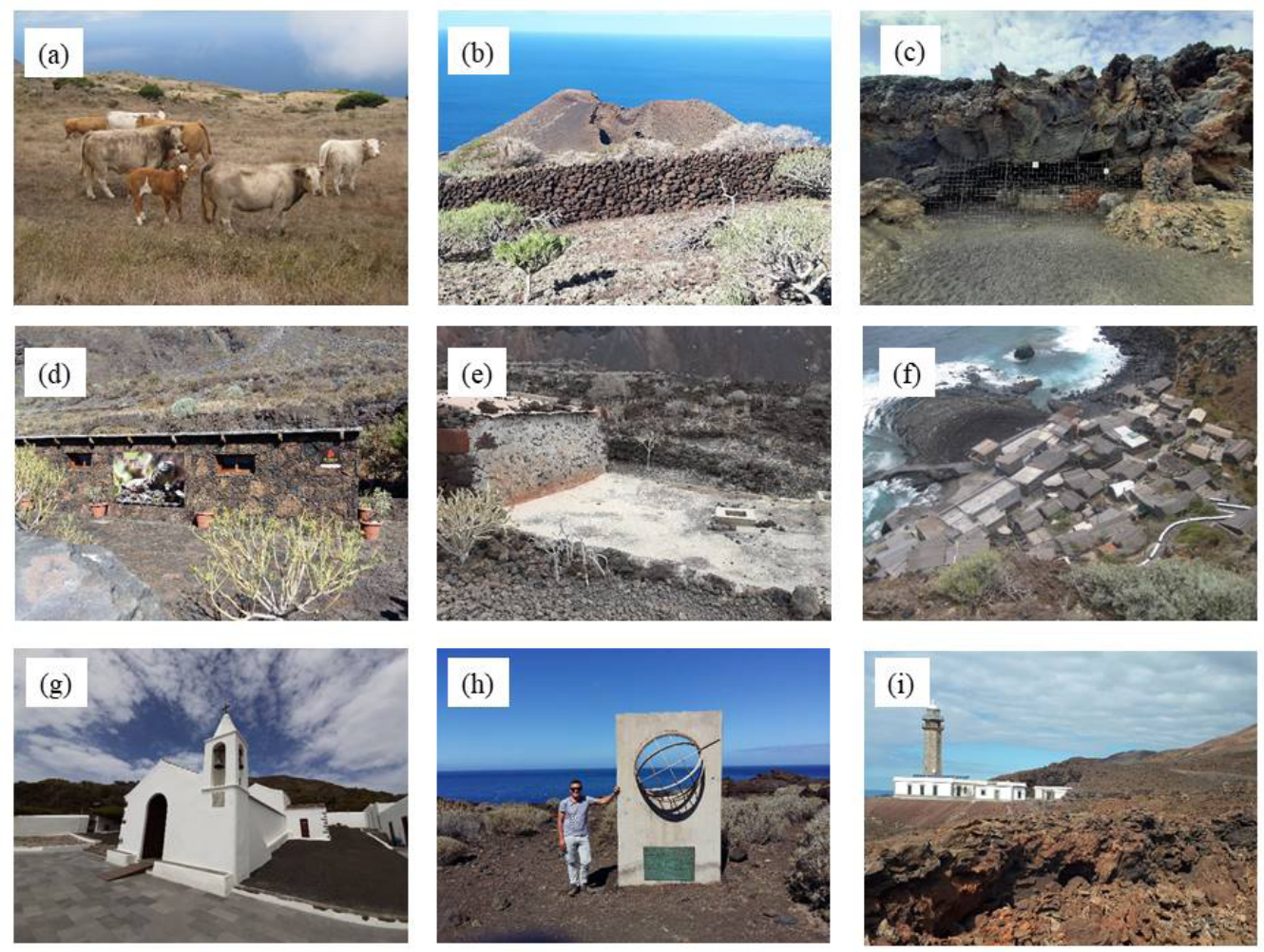

Fuente: archivo de autores. 
de abordar la evaluación del patrimonio geomorfológico de diferentes lugares entronca directamente con la definición de geomorfositio (Panizza, 2001) y su interés como recurso socioeconómico (Reynard \& Panizza, 2005). En este sentido, teniendo en cuenta estos aspectos, el estudio de los geomorfositios debe tener un marcado carácter aplicado como se refleja en la creación y gestión de los geoparques. Pero al mismo tiempo, deben estar relacionados con la aproximación más geográfica del geoturismo (Millan, 2011; Tourtellot, 2000; Stoke et al., 2003; Pralong, 2006; Dowling \& Newsone, 2018; Sánchez-Cortez y Simbaña-Tasiguano, 2018; Dóniz-Páez et al., 2019c,). En este sentido, las ideas expuestas conectan directamente con el objetivo de este trabajo de identificar, inventariar, seleccionar y evaluar geomorfositios para hacer propuestas de geoturismo que diversifiquen la oferta de ocio en El Hierro.

\section{Conclusiones}

En este trabajo se ha llevado a cabo la valoración del geopatrimonio de veinte lugares de interés geomorfológico del Geoparque global UNESCO de El Hierro siguiendo una metodología previamente aplicada con éxito en otros espacios naturales protegidos de naturaleza volcánica. El estudio pretende avanzar en la aproximación más geográfica del geoturismo integrando tanto el patrimonio natural como el cultural de los geomorfositios, como ya se contempla en muchos geoparques mundiales. La propuesta de esta investigación tiene un marcado carácter aplicado, ofreciendo a los gestores del geoparque y las empresas turísticas una selección de espacios de alto valor geopatrimonial donde llevar a cabo nuevas actividades geoturísticas. Aun así, queda mucho por hacer en el desarrollo de metodologías de valoración del geopatrimonio que permitan perfilar sus múltiples especificidades y del geoturismo en su concepción más global, basado en una interrelación real de los valores naturales y culturales de los lugares de interés geomorfológico. Al mismo tiempo, estas metodologías deberían incluir cualitativa y cuantitativamente la opinión de la demanda sobre el geoturismo de cara a la valoración y, por tanto, selección de los lugares más valorados. Un objetivo dirigido, por tanto, a una ampliación del significado estrictamente geológico de la raíz "geo" a una acepción más geográfica de dicha raíz que ayude a consolidar esta forma "novedosa" de hacer turismo en la naturaleza.

\section{Referencias}

AROUCA DECLARATION. International Congress of Geotourism, Geopark Arouca, Portugal, 2011 (9/11/2019) http://www.europeangeoparks.org/?p=223

AULINAS, M., DOMÍNGUEZ, D., RODRÍGUEZ-GONZÁLEZ, A., CARMONA, H., FERNÁNDEZ-TURIEL, J., PÉREZ-TORRADO, F., CARRACEDO, J., ARIENZO, I. \& D'ANTONIO, M. The Holocene volcanism at El Hierro: insights from petrology and geochemistry. Geogaceta, 2019, Vol. 65, p. 35-38.

BECERRA-RAMÍREZ, R. Geomorfología y Geopatrimonio de los volcanes magmáticos de la Región Volcánica del Campo de Calatrava. Tesis Doctoral. Universidad de Castilla-La Mancha, 2013.

BECERRIL, L., GALINDO, I., MARTÍ, J. \& GUDMUNDSSON, A. Three armed rifts or masked radial pattern of eruptive fissures? The intriguing case of el hierro volcano (Canary Islands). Tectonophysics, 2015, Vol. 647-648, p. 33-47. https://doi: 10.1016/j.tecto.2015.02.00 
BECERRIL, L., GALVE, J., MORALES, J., ROMERO, C., SÁNCHEZ, N., MARTí, J. \& GALINDO, I. Volcano-structure of El Hierro (Canary Islands). Journal of Maps, 2016, Vol. 12, No 1, p. 43-52. https:// www.tandfonline.com/doi/full/10.1080/17445647.2016.1157767

BELTRÁN YANES, E. \& DÓNIZ-PÁEZ, J. 8320, campos de lava y excavaciones naturales. En: VVAA. Bases ecológicas preliminares para la conservación de los tipos de hábitat de interés comunitario en España. Madrid: Ministerio de Medio Ambiente, y Medio Rural y Marino, 2009, p. 1-124.

BOUZEKRAOUI, H., BARAKAT, A., TOUHAMI, F., MOUADDINE, A. \& El YOUSSI, M. Inventory and assessment of geomorphosites for geotourism development: A case study of Aï Bou Oulli valley (Central High-Atlas, Morocco). Area, 2017, Vol. 50, p. 331-343. https://doi:10.1111/area.12380

CARCAVILLA, L., BELMONTE, A., DURÁN, J. \& HILARIO, A. Geoturismo: concepto y perspectivas en España. Enseñanza de las Ciencias de la Tierra, 2011, Vol. 19, № 1, p. 81-94. https://www.raco.cat/ index.php/ECT/article/view/244381/331353\%20

CARRACEDO, J. Los volcanes de las Islas Canarias. IV. La Palma, La Gomera, El Hierro. Madrid, Rueda, 2008.

CARRACEDO, J. Erupciones recientes de Canarias. Casos confusos, curiosos y terroríficos. Santa Cruz de Tenerife: Añazo-Nova, 2020.

DEL ARCO, M., WILDPRET, W., PÉREZ DE PAZ, P.L., RODRÍGUEZ, O., ACEBES, J.R., GARCÍA, A., MARTíN, V.E., REYES, J.A., SALAS, M., DÍAZ, M.A., BERMEJO, J.A., GONZÁLEZ, R., CABRERA, M.V., \& GARCÍA, S. Mapa de Vegetación de Canarias. Santa Cruz de Tenerife: Grafcan-Cartografía de Canarias, 2006.

DE LA CRUZ-MODINO, R. Turismo, pesca y gestión de recursos en la Reserva marina Punta de la Restinga-Mar de las Calmas (El Hierro, Islas Canarias) y el área natural protegida de las Islas Medas (I'Estartit, Girona). Universidad de La Laguna: La Laguna, 2008.

DÓNIZ-PÁEZ, J. Los volcanes basálticos monogénicos de Tenerife. Los Realejos: Ayto. Los Realejos, 2009.

DÓNIZ-PÁEZ, J. Volcanic geomorphological classification of the cinder cones of Tenerife (Canary Islands, Spain). Geomorphology, 2015, Vol. 228, p. 432-447. https://doi.org/10.1016/j.geomorph.2014.10.004

DÓNIZ-PÁEZ, J., BECERRA-RAMÍREZ, R., GONZÁLEZ, E., GUILLÉN, C. \& ESCOBAR, E. Geomorphosites and Geotourism in volcanic landscapes: The example of La Corona del Lajial Cinder cone (EI Hierro, Canary Islands, Spain). Geojournal of Tourism and Geosites, 2011, Vol. IV, No 2, p. 185-197. http://gtg.webhost.uoradea.ro/PDF/GTG-2-2011/3_98_Doniz_Paez.pdf

DÓNIZ-PÁEZ, J., HERRERA-RAMOS, H. \& TOLEDO-MARTíN. M. Itinerario geoturístico en el geoparque mundial Unesco de El Hierro (Canarias, España) como estrategia de diversificación de su 
oferta turística. En: MARTíN-GONZÁLEZ, E., COELLO BRAVO, J. \& VEGAS, J. (eds.). Actas de la XIII Reunión Nacional de la Comisión de Patrimonio Geológico. IGME: Madrid, 2019a, p. 123-128.

DÓNIZ-PÁEZ, J., HERNÁNDEZ, W., PRZEOR, M. \& PÉREZ, N. Guía geoturística de Tenerife. Santa Cruz de Tenerife: Involcan, 2019b.

DÓNIZ-PÁEZ, J., BECERRA-RAMÍREZ, R. \& ANCEAUME-CHINEA, L. Ruta volcánica en el geoparque mundial Unesco de El Hierro (Canarias, España): geozona de Orchilla. En: MARTíN-GONZÁLEZ, E., COELLO BRAVO, J. \& VEGAS, J. (eds.). Actas de la XIII Reunión Nacional de la Comisión de Patrimonio Geológico. IGME: Madrid, 2019c, p. 111-116.

DOWLING, R. Global geotourism: An emerging form of sustainable tourism. Czech Journal of Tourism, 2013, Vol. 2, No 2, p. 59-79. http://www.czechjournaloftourism.cz/cislo/en/102/02-2013/\#clanek104

DOWLING R, \& NEWSOME, D. Geotourism: definition, characteristics and international perspectives. En: DOWLING R, \& NEWSOME, D. (eds.) Handbook of Geotourism. Cheltenham: Edward Elgar, 2018, p. 1-22.

ERFURT-COOPER, P. Geotourism development and management in volcanic regions. En: DOWLING R, \& NEWSOME, D. (eds.) Handbook of Geotourism. Cheltenham: Edward Elgar, 2018, p. 152-167.

FARSANI, N., COELHO, C. \& COSTA, C. Tourism Crisis Management in Geoparks through Geotourism Development. Revista de Turismo \& Desenvolvimento, 2012, Vol. 17-18, p. 1627-1638.

FERNÁNDEZ-PELLO, L. Los paisajes naturales de la isla de El Hierro. Cabildo de El Hierro: Santa Cruz de Tenerife, 1986.

GAO, W., Li, J., MAO, X. \& LI, H. Geological and Geomorphological Value of the Monogenetic Volcanoes in Wudalianchi National Park, NE China. Geoheritage, 2013, Vol. 5, p. 3-85. https://doi. org/10.1007/s12371-013-0077-5

GONZÁLEZ, M., SERRANO, E. \& GONZÁLEZ, M. Lugares de interés geomorfológico, geopatrimonio y gestión de espacios naturales protegidos: el Parque Natural de Valderejo (Álava, España). Revista de Geografía Norte Grande, 2014, Vol. 59, p. 45-64.

GONZÁLEZ-TRUEBA; D. \& SERRANO, E. La valoración del patrimonio geomorfológico en espacios naturales protegidos. Su aplicación al Parque Nacional de los Picos de Europa. Boletín Asociación Geógrafos Españoles, 2008, Vol. 47, p. 174-194. https://bage.age-geografia.es/ojs/index.php/ bage/article/view/2035

HENRIQUES, M. \& NETO, K. Geoheritage at the Equator: Selected Geosites of São Tomé Island (Cameron Line, Central Africa). Sustainability, 2015, Vol. 7, 648-667; doi:10.3390/su7010648. https:// www.mdpi.com/2071-1050/7/1/648 
HERNÁNDEZ, R. \& SANTANA, A. Destinos turísticos maduros ante el cambio. Reflexiones desde Canarias. Universidad de La Laguna: La Laguna, 2010.

HOSE, A. Towards a history of geotourism: definitions, antecedents and the future. Geological Society, London, 501 Special Publications, 2008, Vol. 300, № 1, p. 37-6. https://sp.lyellcollection. org/content/300/1/37

HOSE, A. Selling the story of Britain's stone. Environmental Interpretation, 1995, Vol. 10, No 2, p. 16-17.

ISTAC. 2019. (09/10/2019). http://www.gobiernodecanarias.org/istac/

ISTAC. 2020. (06/06/2020). http://www.gobiernodecanarias.org/istac/

LIMA, E., NUNES, J., COSTA, M. \& MACHADO, M. Basis for the geological heritage management in the Azores Archipelago (Portugal). Journal of Integrated Coastal Zone Management, 2014, Vol. 14, No 2, p. 301-319.

MARZOL, V. El clima. En: MORALES, G. \& PÉREZ R., (ed). Gran atlas temático de Canarias. Santa Cruz de Tenerife: Interinsular canaria, 2000, p. 87-106.

MEGERSSA, L., RAPPRICH, V., NOVOTNÝ, R., VERNER, K., ERBAN, V., LEGESSE, F. \& MANAYE, M. Inventory of key geosites in the Butajira Volcanic Field: perspective for the first geopark in Ethiopia. Geoheritage, 2019, Vol. 11, p. 1643-1653 https://doi.org/10.1007/s12371-019-00393-y

MIKHAILENKO, A. \& RUBAN, D. Geo-Heritage Specific Visibility as an Important Parameter in Geo-Tourism Resource Evaluation. Geosciences, 2019, Vol. 9, 146; doi:10.3390/geosciences9040146

MILLÁN, M. La función didáctica del geoturismo. Propuesta para la Región de Murcia. Gran Tour: Revista de Investigaciones Turísticas, 2011, Vol. 4, p. 62-93.

NATIONAL GEOGRAPHIC, what is geotourism? Center for Sustainable Destinations. 2010. (09/10/2019). www.nationalgeographic.com/travel/sustainable, 15.06.2012

NÉMETH, K. \& MOUFTI, M.R. Geoheritage Values of a Mature Monogenetic Volcanic Field in Intra-continental Settings: Harrat Khaybar, Kingdom of Saudi Arabia. Geoheritage, 2017, Vol. 9, p. 311-328. https://doi.org/10.1007/s12371-017-0243-2

NÉMETH, K., WU, J., SUN, C. \& LIU, J. Update on the Volcanic Geoheritage Values of the Pliocene to Quaternary Arxan-Chaihe Volcanic Field, Inner Mongolia, China. Geoheritage, 2017, Vol. 9, p. 279-297. https://doi.org/10.1007/s12371-017-0224-5

OMT. 2019. (09/10/2019). http://www2.unwto.org/es 
OLSON, K. \& DOWLING, R. Geotourism and Cultural Heritage. Geoconservation Research, 2018, Vol. 1, No 1, p. 37-41. https://doi:10.30486/GCR.2018.540021

NEWSOME, D. \& DOWLING, R. Geotourism: The Tourism of Geology and Landscape. Oxford: Goodfellow Publishers, 2010.

ÓLAFSDÓTTIR, R. \& DOWLING, R. Geotourism and Geoparks-A Tool for Geoconservation and Rural Development in Vulnerable Environments: A Case Study from Iceland. Geoheritage, 2014, Vol. 6, No 1. P. 71-87. https://link.springer.com/article/10.1007/s12371-013-0095-3

ÓLAFSDÓTTIR, R. \& TVERIJONAITE, E. Geotourism: a systematic literature review. Geosciences, 2018, Vol. 8, No 7, 234; https://doi.org/10.3390/geosciences8070234.

PANIZZA, M. Geomorphosites: concepts, methods and examples of geomorphological survey. Chinese Sciencie Bulletin, 2001, Vol. 6, p. 4-6.

PÁSKOVÁ, M. \& ZELENKA, J. Sustainability Management of Unesco Global Geoparks. Sustainable Geoscience and Geotourism, 2018, Vol. 2, p. 44-64. https://www.scipress.com/SGG.2.44

PEDRAZZI, D., BECERRIL, L., MARTÍ, J., MELETLIDIS, S. \& GALINDO, I. Explosive felsic volcanism on El Hierro (Canary Islands). Bulletin of Volcanology, 2014, Vol. 76:863 https://doi10.1007/s00445014-0863-1

PÉREZ-UMAÑA, D., QUESADA, A., DE JESÚS ROJAS, J., ZAMORANO, J., DÓNIZ-PÁEZ, J. \& BECERRA-RAMÍREZ, R. Comparative Analysis of Geomorphosites in Volcanoes of Costa Rica, Mexico, and Spain. Geoheritage, 2019, Vol. 11, № 2, p. 545-559. https://link.springer.com/article/10.1007/ s12371-018-0313-0

PÉREZ-UMAÑA, D., QUESADA, A. \& TEFOGOUM, G. Geomorphological heritage inventory of Irazú volcano, Costa Rica. International Journal of Geoheritage and Parks, 2020, Vol. 8, p. 31-47. https:// www.sciencedirect.com/science/article/pii/S2577444119300577

PRALONG, J.P. Geotourism: A new form of tourism utilising natural landscapes and based on imagination and emotion. Tourism Review, 2006, Vol. 61, No 3, p. 20-25. https://www.emerald.com/ insight/content/doi/10.1108/eb058476/full/html

QUESADA-ROMÁN, A. \& PÉREZ-UMAÑA, D. Tropical Paleoglacial Geoheritage Inventory for Geotourism Management of Chirripó National Park, Costa Rica. Geoheritage, Vol. 12:58, https://doi. org/10.1007/s12371-020-00485-0

QUINTERO, Y. Los efectos de la erupción submarina en la evolución del turismo en El Hierro: pasado, presente y futuro. Trabajo Fin de Grado. La Laguna: EUTI-Universidad de la Laguna, 2013.

RISO, C., NÉMETH, K. \& ULRIKE, M. Proposed geosites on Pliocene to Recent pyroclastic cone fields in Mendoza, Argentina. Zeitschrift der Deutschen Gesellschaft für Geowissenschaften, 2006, Vol. 157, No 3, p. 477-490. https://doi:10.1127/1860-1804/2006/0157-0477 
RUBAN, D. Geotourism-A geographical review of the literatura. Tourism Management Perspectives, 2015, Vol. 15, p. 1-15. https://doi.org/10.1016/j.tmp.2015.03.005

REYNARD, E. \& PANIZZA, M. Geomorphosites: definition, assessment and mapping: an introduction. Geomorphologie relief, processus, environnement, 2005, Vol. 11, № 3, p.177-180. https://journals.openedition.org/geomorphologie/336

SÁNCHEZ-CORTEZ, J. \& SIMBAÑA-TASIGUANO, M. Los Geoparques y su implantación en América Latina. Estudios Geográficos, 2018, Vol. LXXIX/285, p. 445-467. https://doi.org/10.3989/estgeogr.201817

SERRANO, E. \& GONZÁLEZ TRUEBA, J. Assessment of geomorphosites in natural protected areas: the Picos de Europa National Park (Spain). Géomorphologie: relief, processus, environnement, 2005, Vol. 3, p. 197-208. https://journals.openedition.org/geomorphologie/364

SERRANO, E., GABRIEL DUQUE DEL CORRAL, P., FERNÁNDEZ, V., GENTO, I. \& RELLO, D. Patrimonio natural y geomorfología. Lugares de interés geomorfológico del Parque Natural Sierra de Cebollera. Zubia, 2018, Vol. 36, p. 45-81. https://dialnet.unirioja.es/servlet/articulo?codigo=6869027

STOKES, A., COOK, S. \& DREW, D. Geotourism: The New Trend in Travel. The Travel Industry Association of America (TIA) and National Geographic Traveler. Washington, DC: National Geographic, 2003.

TOURTELLOT, J.B. Geotourism for Your Community. National Geographic Drafts, p. 2. Washington, DC: National Geographic, 2000.

TUROĞLU, H. Karasu Grabeni (Hatay, Türkiye) Bazalt Morfolojisinde Volkanik Jeomorfosit Değerlendirmesi / Volcanic Geomorphosites Assessment Within The Basalt Morphology of The Karasu Graben (Hatay, Turkey), Jeomorfolojik Araştırmalar Dergisi / Journal of Geomorphological Researches, 2020, Vol. 4, p. 62-80.

ZANGMO-TEFOGOUM, G., QUESADA-ROMÁN, A. \& PÉREZ-UMAÑA, D. Geomorphosites inventory in the Eboga Volcano (Cameroon): contribution for geotourism promotion. Géomorphologie: relief, processus, environnement, 2020, Vol. 26, No 1, p. 19-33. doi.org/10.4000/geomorphologie.14006

ZANGMO-TEFOGOUM, G., KAGOU, A., NKOUATHIO, D., GOUNTIÉ, M. \& KAMGANG, P. The volcanic geoheritage of the Mount Bamenda Calderas (Cameroon line): assessment for geotouristic and geoeducational purposes. Geoheritage, 2017, Vol. 9, p. 255-278. https://doi.org/10.1007/s12371016-0177-0 